\section{Commentary: The mitral annulus in normal valve function. Does shape matter?}

\author{
Vincent Chan, MD, MPH, FRCSC, FAHA, \\ Marc Ruel, MD, MPH, FRCSC, FAHA, and \\ Thierry G. Mesana, MD, PhD, FECTS
}

In this study, the authors from New York University summarize their experience with the annuloplasty system, which they have pioneered, namely the C-G Futureband (Medtronic, Inc, Minneapolis, Minn). ${ }^{1}$ As the authors have noted in their review, the mitral annulus is dynamic and changes shape on the basis of the pathology involved. In the case of degenerative mitral regurgitation, the mitral annulus becomes more circular. Therefore, mitral annuloplasty reapproximates normal mitral annulus shape and has become a standard component of surgical mitral valve repair.

The authors of this review note the considerations of mitral annuloplasty, specifically functional stenosis, and the potential for systolic anterior motion of the mitral valve with annular restriction. Overall, expert centers have published favorable results using a variety of repair techniques and indeed a complete annuloplasty remains the most widely used annuloplasty system. ${ }^{2}$

However, when assessing resting mitral valve gradients in individuals without mitral valve disease, our group found an average of $<3 \mathrm{~mm} \mathrm{Hg}$ to be physiologic. Indeed, when we used this threshold to compare patients post mitral repair, we found that patients with a mean gradient of $>3 \mathrm{~mm} \mathrm{Hg}$ at rest were more likely to have

\footnotetext{
From the Division of Cardiac Surgery, University of Ottawa Heart Institute, Ottawa, Ontario, Canada.

Disclosures: The authors reported no conflicts of interest.

The Journal policy requires editors and reviewers to disclose conflicts of interest and to decline handling or reviewing manuscripts for which they may have a conflict of interest. The editors and reviewers of this article have no conflicts of interest.

Received for publication Oct 15, 2021; revisions received Oct 15, 2021; accepted for publication Oct 15, 2021; available ahead of print Oct 21, 2021.

Address for reprints: Vincent Chan, MD, MPH, FRCSC, FAHA, H3405A-40 Ruskin

St, Ottawa, Ontario K1Y 4W7, Canada (E-mail: vchan@ottawaheart.ca).

JTCVS Techniques 2021;10:45-6

2666-2507

Copyright (C) 2021 The Author(s). Published by Elsevier Inc. on behalf of The American Association for Thoracic Surgery. This is an open access article under the CC BY-NC-ND license (http://creativecommons.org/licenses/by-nc-nd/4.0/).

https://doi.org/10.1016/j.xjtc.2021.10.034
}

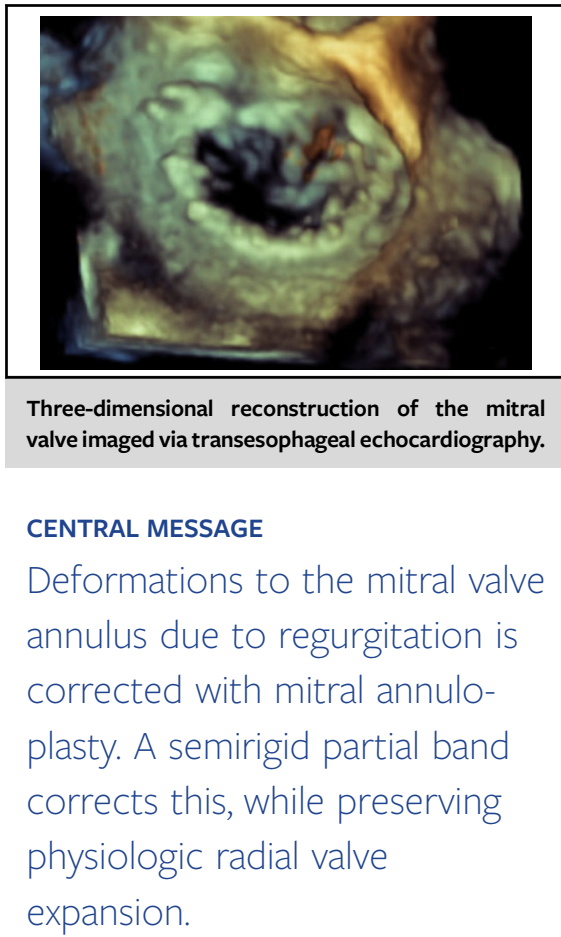

elevated gradients at peak exercise with associated higher B-type natriuretic peptide levels, lower exercise capacity, and worse quality of life compared with patients with a lower transmitral repair gradient at rest. ${ }^{3}$ In a substudy, a higher transmitral repair gradient at peak exercise was more commonly observed in patients who received a complete ring annuloplasty versus those who received a partial band. ${ }^{4}$ This observation was more pronounced among patients who received an annuloplasty band $<30 \mathrm{~mm}^{4}{ }^{4}$

In our opinion, the C-G Futureband has several features that might be beneficial to surgical repair of degenerative mitral regurgitation. Indeed, we find that the semi-rigid aspect of the annuloplasty, which limits anterior-posterior deformation, also maintains radial expansion of the valve, which might be more physiologic. The partial annuloplasty might also allow for better anterior leaflet excursion and preservation of the natural saddle shape of the mitral annulus.

However, is an annuloplasty needed and does the shape of the mitral orifice even matter? The advent of transcatheter edge-to-edge repair (TEER) and the favorable early results in select degenerative cases highlight the evolution of mitral valve therapies. ${ }^{5}$ Indeed, the anterior-posterior 
dimension of the mitral valve appears to be maintained with the rigidity of the edge-to-edge device, although long-term results with TEER remain undetermined. As well, longterm TEER results might vary in patients with a large mitral annulus.

Overall, the surgical repair of degenerative mitral regurgitation remains the gold-standard therapy and is associated with favorable early and late results in expert centers. This development of expertise has also lent to a variety of approaches and strategies. Fundamentally, the goal is to reapproximate mitral valve physiology with the best result for the patient. This highlights the need for longitudinal valve assessment to determine the ideal treatment options.

\section{References}

1. James L, Grossi EA, Loulmet D, Galloway AC. Semirigid posterior annuloplasty band: Reshaping the mitral orifice while preserving its physiology. J Thorac Cardiovasc Surg Tech. 2021;10:37-42.

2. Chan V, Mazer CD, Ali FM, Qua A, Ruel M, de Varennes B, et al. Randomized, controlled trial comparing mitral valve repair with leaflet resection versus leaflet preservation on functional mitral stenosis: the CAMRA CardioLink-2 Study. Circulation. 2020;142:1342-50.

3. Chan K, Chen SY, Chan V, Hay K, Mesana T, Lam K. Functional significance of elevated mitral gradients after repair for degenerative mitral regurgitation. Circ Cardiovasc Imaging. 2013;6:1041-7.

4. Mesana T, Lam BK, Chan V, Chen K, Ruel M, Chan K. Clinical evaluation of functional mitral stenosis after mitral valve repair for degenerative disease: potential affect of surgical strategy. J Thorac Cardiovasc Surg. 2013;146:1418-23.

5. Feldman T, Kar S, Elmaria S, Smart S, Trento A, Siegel R, et al. Randomized comparison of percutaneous repair and surgery for mitral regurgitation: 5-year results of EVEREST II. J Am Coll Cardiol. 2015;66:2844-54. 